HERMAN, Michael. 2001. Intelligence Services in the Information Age: Theory and Practice. Londres : Frank Cass.

\title{
SERVIÇOS DE INTELIGÊNCIA NA ERA DA INFORMAÇÃO?
}

\author{
Marco Aurélio C. Cepik \\ Universidade Federal de Minas Gerais
}

O novo livro de Michael Herman apresenta três desenvolvimentos importantes em relação ao trabalho anterior do autor, Intelligence Power in Peace and War, publicado em 1996.

Em primeiro lugar, situa de maneira mais precisa o papel da atividade de inteligência nos processos de tomada de decisões governamentais, em uma época em que as novas tecnologias de informações e comunicação (TICs) aumentaram enormemente a quantidade e a diversidade de fluxos informacionais e de conhecimentos especializados em qualquer área relevante de política pública. Em especial, Herman analisa com mais detalhe e precisão analítica as diferenças e comunalidades entre a atividade de inteligência e a diplomacia, por um lado, e entre inteligência e as funções militares de reconhecimento, vigilância e aquisição de alvos (ISTAR), por outro lado.

Em segundo lugar, o novo livro avança na comparação internacional entre diferentes componentes organizacionais dos serviços de inteligência. Não que o autor tenha reformulado de alguma forma seu tipoideal baseado no modelo anglo-saxão, cuja aderência a qualquer caso concreto seria decrescente desde um núcleo formado pelos sistemas de inteligência dos Estados Unidos e da Grã-Bretanha, passando pelas excolônias britânicas, pela Europa continental e atingindo seu ponto de menor força descritiva quando se trata de analisar o modelo soviético de inteligência e os países asiáticos. Mas há, em Intelligence Services in the Information Age, elementos muito mais sólidos para estudos efetivamente comparativos entre países, especialmente entre o próprio caso britânico e o dos Estados Unidos, ou entre diferentes momentos históricos de uma mesma organização.

Em terceiro lugar, Michael Herman enfrenta aqui o problema mais geral dos efeitos das atividades unilaterais de coleta de inteligência para a segurança internacional. Como pode-se imaginar, esse tipo de questão normativa não é comum no âmbito dos Intelligence Studies. Tipicamente, apenas se dá por suposto que as plataformas tecnológicas, os recursos humanos e organizacionais - enfim, todo o labor da atividade de inteligência - é uma parte significativa e impossível de ser eliminada das relações internacionais. Entretanto, raramente os autores que estudam o fenômeno fazem perguntas normativas a si mesmos, tais como se deveria haver mais ou menos investimento em atividades de inteligência, ou se é correto moralmente ou desejável que tais atividades sejam praticadas pelos governos contemporâneos. Embora a resposta de Herman sobre a desejabilidade de um menor uso de meios intrusivos de coleta de informações (espionagem e sigint ${ }^{1}$ ) sobre os estados nacionais "decentes" esteja baseada numa distinção precaríssima entre o caráter supostamente mais ou menos ofensivo dos meios, sua ênfase no valor decrescente da inteligência em áreas de políticas públicas não relacionadas à segurança nacional pode ter desdobramentos interessantes em vários planos de análise, inclusive numa área pouco desenvolvida até aqui pela literatura de Intelligence Studies e que me parece premente: a de projeto de forças.

No "Posfácio" escrito logo após os atentados terroristas de 11 de setembro de 2001 nos Estados Unidos, Michael Herman discute os possíveis impactos desses eventos sobre as prioridades e métodos da área de inteligência, tanto em termos realistas e pragmáticos, quanto do ponto de vista dos desideratos e riscos morais associados à "guerra contra o terrorismo". Bem, como mencionei uma parte específica do livro, o fato de

1 Sigint, ou signal intelligence, é a inteligência obtida a partir da interceptação e da decodificação de sinais eletrônicos, comunicacionais e outros. 
Intelligence Services in the Information Age reunir textos escritos ao longo de cinco anos deve ser destacado neste ponto da resenha. $\mathrm{O}$ autor não pretendeu revestir os materiais reunidos com uma unidade artificialmente construída a posteriori. Ainda assim, por perseguir uma agenda de pesquisas consistente com os alicerces construídos em seu trabalho anterior, em sua diversidade os ensaios apontam na tripla direção mencionada anteriormente.

Na primeira parte do livro ("Intelligence and Information") estão reunidos três ensaios de maior fôlego, um sobre inteligência e informações (capítulo 1), outro sobre inteligência e diplomacia (capítulo 2) e um terceiro sobre o lugar da atividade de inteligência na chamada Revolução dos Assuntos Militares (capítulo 3). Na segunda parte ("Living with the US: British and Other Systems") temos cinco capítulos, sendo que o capítulo 4 oferece uma síntese bastante útil da estrutura organizacional, custos agregados, relações entre coleta e análise e outros aspectos da "maquinaria" britânica de inteligência. Também é nesse texto que Herman defende que a Grã-Bretanha desenvolva uma capacidade aeroespacial própria na área de coleta de imagens e sinais. O capítulo 5 comenta especificamente a trajetória do Joint Intelligence Committee britânico, e o breve capítulo 6 oferece um contraste direto entre os dois sistemas nacionais de inteligência, dos Estados Unidos e da GrãBretanha. O papel central da superpotência americana na aliança contra a União Soviética durante a Guerra Fria foi evidente também na área de inteligência. Assim, enquanto o capítulo 7 analisa a contribuição específica e as capacidades de inteligência da Noruega, o capítulo 8 discute as inúmeras idas-e-vindas da Nova Zelândia no pacto de compartilhamento de inteligência dos países anglo-saxões, o UKUSA. A terceira parte do livro ("Historical Lessons") começa com uma avaliação preliminar sobre o peso relativo e as contribuições específicas da inteligência durante a Guerra Fria (capítulo 9), segue com dois textos fortemente autobiográficos nos quais o autor discute o tema da qualidade das análises de inteligência para o governo (capítulo 10) e os efeitos do segredo e da "excepcionalidade" para o funcionamento das organizações de criptologia (capítulo 11), e termina com uma relativização do valor da separação excessiva entre coletores, analistas e consumidores no sistema britânico, em particular sobre os desafios colocados para um órgão como o Defense Intelligence Staff (capítulo 12). A parte quatro do livro ("Intelligence and a Better World") compreende o capítulo 13, um texto sobre os limites e possibilidades de uma regulamentação internacional das atividades de inteligência. Por fim, o "Posfácio" trata do impacto dos atentados de 11 de setembro de 2001 e a pressão que tal evento tenderia a desencadear no sentido da formação de um sistema internacional de inteligência sobre terrorismo, crime organizado e tráfico de drogas.

Não creio que seja o caso de comentar extensamente cada um dos capítulos do novo livro de Michael Herman. Vale destacar, entretanto, que se trata de uma obra importante para os estudantes e professores de Relações Internacionais e de Ciência Política, para os pesquisadores das áreas de Estudos Estratégicos, Políticas Públicas e Ciência da Informação, bem como para os gestores públicos nas áreas de política externa, política de defesa nacional e políticas de provimento de ordem pública. Menos sistemático, porém mais vívido do que seu trabalho anterior, nessa coletânea de ensaios Herman (nascido em 1929) parece mais confortável na sua tripla condição de ex-analista do Government Communications Headquarters (GCHQ) e ex-Secretário do Joint Intelligence Committee britânico e atual Fellow do St. Antony's College da Universidade de Oxford. Embora alguns comentadores (e. g. Robert Steele) tenham declarado que Intelligence Services in the Information Age seria inferior ao livro anterior do próprio Herman, creio que essa comparação é equivocada. Além de desenvolver várias idéias esboçadas em Intelligence Power in Peace and War, o novo livro traz casos históricos, análises comparativas e questões inéditas e relevantes para o campo dos Intelligence Studies. Em minha opinião, essa coletânea de ensaios de Michael Herman deve ser lida em conjunto com o livro de 1996.

Naturalmente, essa é uma opinião bastante pessoal. Afinal, em minha própria tese doutoral, concluída apenas alguns meses antes do lançamento do novo trabalho de Herman, é nítida a influência do trabalho anterior desse autor inglês. Em um campo de estudos no qual ainda predominam abordagens estritamente histórico-descritivas e/ou francamente paroquiais, Michael Herman produziu uma primeira síntese teórica sobre o que seja a atividade de inteligência no Estado contemporâneo. Na medida em que procurei apropriarme daquela síntese, procurei corrigir seu viés etnocêntrico através de exercícios comparativos, tentando ir além no esclarecimento de alguns conceitos e dinâmicas operacionais e persegui uma agenda específica de problemas de institucionalização, mas reconheço prontamente o valor da reflexão de Michael Herman para qualquer pesquisador sério nessa área tão cinzenta da ação governamental contemporânea. 
Marco Aurélio C. Cepik (mcepik@fafich.ufmg.br) é Doutor em Ciência Política pelo Instituto Universitário de Pesquisas do Rio de Janeiro (IUPERJ), Professor do Departamento de Ciência Política da Universidade Federal de Minas Gerais (UFMG) e Pesquisador do Grupo de Estudos Estratégicos da Universidade Federal do Rio de Janeiro (UFRJ).

\section{REFERÊNCIAS BIBLIOGRÁFICAS}

BERKOWITZ, B. D. \& GOODMAN, A. E. 2000. Best Truth : Intelligence in the Information Age. New Haven : Yale University Press.

CEPIK, M. A. C. 1997. Inteligência, política e poder no Estado contemporâneo. Revista de Sociologia e Política, Curitiba, n. 9, p. 193-196, nov.

.2001a. Serviços de inteligência : agilidade e transparência como dilemas de institucionalização. Rio de Janeiro. Tese (Doutorado em Ciência Política). Instituto Universitário de Pesquisas do Rio de Janeiro.

.2001b. Segurança nacional e controle público : limites dos mecanismos institucionais existentes. Contexto Internacional, Rio de Janeiro, v. 23, n. 2, p. 295-359, jul.-dez.

FRY, M. G. \& HOCHSTEIN, M. 1993. Epistemic Communities : Intelligence Studies and International Relations. Intelligence and National Security, London, v. 8, n. 3, p. 14-28, July.

HERMAN, M. 1996. Intelligence Power in Peace and War. Cambridge, UK : Cambridge University Press.

SWENSON, R. (ed.). 1997. Intelligence for Multilateral Decision and Action. Washington : JMIC Press. 